\title{
ANALYSIS OF PRODUCTION PERFORMANCE OF TAMILNADU NEWSPRINT AND PAPERS LTD - CASE STUDY
}

\author{
B.Vasumathi \\ Department of Computer \\ Science and Applications, \\ PGP College of Arts \& Science \\ Namakkal, TamilNadu
}

\author{
A.Saradha \\ Department of Computer \\ Science and Technology, \\ Indian Road Transport and \\ Technology, \\ Erode, Tamil Nadu
}

\author{
K.Venkatachalam \\ Department of Commerce, \\ PGP College of Arts \& \\ Science, Namakkal, \\ TamilNadu
}

\begin{abstract}
Every day, Tamilnadu Newsprint and Papers Ltd managers must make decisions about Production delivery without knowing what will happen in the future. Forecasts enable them to anticipate the future and plan, many forecasting methods are available to Tamilnadu Newsprint and Papers Ltd managers for planning, to estimate future demand or any other issues at hand. However, for any type of forecast to bring about later success, it must follow a step-by-step process comprising five major steps: 1) goal of the forecast and the identification of resources for conducting it; 2) time horizon; 3) selection of a forecasting technique; 4) conducting and completing the forecast; and 5) monitoring the accuracy of the forecast. Accordingly Linear Regression method is a widely used to predict this kind of demand. In this paper, we forecast the Production of Papers in TamilNadu Newsprint and Papers Ltd from the past 15 years of Production using the Linear Regression method

Keywords: Trend analysis; Linear Regression; Forecast Accuracy
\end{abstract}

\section{INTRODUCTION}

A time series is a sequence of evenly spaced observations taken at regular intervals over a period of time (such as daily, hourly, weekly, monthly, or yearly). An example of a time series is the Annual production to Tamilnadu Newsprint and Papers Ltd. Forecasts from time-series data assume that future values of the series can be predicted from past values. Analysis of a time series can identify the behavior of the series in terms of trend, seasonality, cycles, irregular variations, or random variations. A trend is a gradual, longterm, upward or downward movement in data. Seasonality refers to short-term, relatively frequent variations generally related to factors such as Shortage of raw material, high cost of production; Sales often experience quarterly and Yearly "seasonal" variations. Cycles are patterns in the data that occur every several years, often in relation to current economic conditions. Such cycles often exhibit wave like characteristics that mimic the business cycle. Irregular variations are "spikes" in the data caused by chance or unusual circumstances (examples: severe weather, labor strike, Water Problem, use of a new high-technology service); they do not reflect typical behavior and should be identified and removed from the data whenever possible. Random variations are residual variations that remain after all other behaviors have been accounted for. Graphing the data provides clues to a manager for selecting the right forecasting method.

Tamil Nadu Newsprint and papers (TNPL) Ltd. was established by the Government of Tamil Nadu in the Year 1976. The company produces Newsprint, Printing and Writing paper using bagasse, a sugarcane residue, as the primary raw material. Their manufacturing facility is located at Kagithapuram in Karur District of Tamil Nadu. Commencing production in 1984 at a modest 90,000 tonnes per annum, the company has made rapid strides and has emerged today as the largest paper mill in India at a single location with a total installed capacity of 400,000 tonnes per annum. TNPL's paper comes from three high end machines of Beloit Walmsley, Voith Paper with a total production capacity of 245,000 tonnes per annum and a third state-of-the-art paper machine with a production capacity of 155,000 tonnes per annum. In this Paper forecast the next 15 years of production in Tamil Nadu Newsprint and papers (TNPL) Ltd using Linear Regression Method. The method is evaluated with different accuracy measures; variance (MSE and MAD), a numerical example shows the next 15 years of production.

\section{TIME SERIES METHOD}

\subsection{Techniques for Trend}

A trend is a gradual, long-term movement caused by changes in population, income, or culture. Assuming that there is a trend present in a data set, it can be analyzed by finding an equation that correlates to the trend in question. The trend may or may not be linear in its behavior. Plotting the data can give a Tamilnadu Newsprint and Papers Ltd manager insight into whether a trend is linear or nonlinear. Forecasting Techniques Based on Linear Regression. By minimizing the sum of the squared errors, which is called the least squares method, regression analysis can be used to create a representative line that has the form:

$y=a+b * x$

where

$\mathrm{y}=$ the predicted (dependent) variable

$\mathrm{x}=$ the predictor (independent) variable

$\mathrm{b}=$ the slope (rise/run) of the data line

$\mathrm{a}=$ the value of $\mathrm{y}$ when $\mathrm{x}$ is equal to zero. 
Consider the regression equation example $y=20+5 x$. The value of $y$ when $x=0$ is 20 , and the slope of the line is 5 .

Therefore, the value of $y$ will increase by five units for each one-unit increase in $\mathrm{x}$. If $\mathrm{x}=15$, the forecast ( $\mathrm{y}$ ) will be 20 $=5(15)$, or 95 units. This equation could be plotted on a graph by finding two points on the line. One of those points can be found in the way just mentioned; putting in a value for $\mathrm{x}$. The other point on the graph would be a (i.e. $\mathrm{y}_{\mathrm{x}}$ at $\mathrm{x}=0$ ). The coefficients of the line, $a$ and $b$, can be found (using historical data) with the following equations:

$$
\begin{aligned}
& b=\frac{n\left(\sum x y\right)-\left(\sum x\right)\left(\sum y\right)}{n\left(\sum x^{2}\right)-\left(\sum x\right)^{2}} \\
& a=\frac{\sum y-b \sum x}{n} .
\end{aligned}
$$

\section{NUMERICAL EXAMPLE}

Table 1 gives an example about the Production data in Tamilnadu Newsprint and Papers Ltd.

\begin{tabular}{|c|c|c|c|c|}
\hline & $\begin{array}{l}\text { PRODUCTION } \\
\text { INMETRIC }\end{array}$ & & & \\
\hline YEAR & TONNES $(\mathrm{Y})$ & $\mathbf{X}$ & $X^{2}$ & $\mathbf{X Y}$ \\
\hline $1997-98$ & 170618 & -7 & 49 & -1194326 \\
\hline 1998-99 & 176075 & -6 & 36 & -1056450 \\
\hline 1999-2000 & 178871 & -5 & 25 & -894355 \\
\hline $2000-01$ & 191106 & -4 & 16 & -764424 \\
\hline 2001-02 & 184267 & -3 & 9 & -552801 \\
\hline $2002-03$ & 167878 & -2 & 4 & -335756 \\
\hline 2003-04 & 182215 & -1 & 1 & -182215 \\
\hline 2004-05 & 196241 & 0 & 0 & 0 \\
\hline $2005-06$ & 230079 & 1 & 1 & 230079 \\
\hline $2006-07$ & 231161 & 2 & 4 & 462322 \\
\hline $2007-08$ & 245471 & 3 & 9 & 736413 \\
\hline 2008-09 & 254903 & 4 & 16 & 1019612 \\
\hline 2009-10 & 245008 & 5 & 25 & 1225040 \\
\hline 2010-11 & 265044 & 6 & 36 & 1590264 \\
\hline 2011-12 & 343306 & 7 & 49 & 2403142 \\
\hline
\end{tabular}

Table 1. Production data

After calculating $\sum \mathrm{x}=0, \sum \mathrm{y}=3262243, \sum \mathrm{xy}=2686545$, $\sum x 2=280, n=14$ substitute into the Equations [2] for $\mathrm{a}$ and $\mathrm{b}$, respectively

$\mathrm{b}=\frac{14(2686545)-0(3262243)}{14(280)-0}=9594.804$

$$
a=\frac{3262243-9594.804(0)}{14}=217482.9
$$

Hence, the regression line is:

$$
\begin{aligned}
& \left.Y_{X}=217482.9+9594.804\right) * 8 \\
& Y=309775.8
\end{aligned}
$$

Table 2 give the results of the Linear Regression method computed based on the above data.

Table 2. The Forecasting Production of Linear Regression Method

PREDICTED
PRODUCTION
INMETRIC TONNES

309775.832

319370.636

328965.44

338560.244

348155.048

357749.852

367344.656

376939.46

386534.264

396129.068

405723.872

415318.676

424913.48

434508.284

444103.088

\section{FORECAST ACCURACY}

\subsection{Mean Square Error(MSE)}

In this section we present and discuss the different measures we use in the forthcoming analyses. Common measures for forecasting errors and its variability are MSE and also Mean Absolute Deviation (MAD). Silver et al (1998) recommend the use of MSE, because MSE is related to standard variation of forecast errors. However MSE is more sensitive to outliers and errors smaller than one due to the squared Function. Which mean that in an evaluation of different forecasting methods MSE and

MAD sometimes presents a different result:

$$
M S E=\frac{1}{T} \sum_{t=1}^{T}\left(x_{t}-\dot{x}_{t}\right)^{2}
$$

$$
M A D=\frac{1}{T_{i}} \sum_{i=1}^{T}\left|X_{2}-\dot{X}_{t}\right|
$$




\section{TEST RESULT}

The data comes from Tamilnadu Newsprint and Papers Ltd; the data covers 15 Years. For an overlook the demand data are also shown in diagrams. Below the result of 15 years of forecast production is shown.

SUMMARY OUTPUT

\begin{tabular}{lr}
\hline \multicolumn{2}{c}{ Regression Statistics } \\
\hline Multiple R & 0.887351052 \\
R Square & 0.78739189 \\
Adjusted R Square & 0.77103742 \\
Standard Error & 23138.64232 \\
Observations & 15 \\
\hline
\end{tabular}

15

ANOVA

\begin{tabular}{lrrrrr}
\hline & $d f$ & \multicolumn{1}{c}{ SS } & \multicolumn{1}{c}{ MS } & \multicolumn{1}{c}{$F$} & Significance $F$ \\
\hline Regression & 1 & 25776871561 & 25776871561 & 48.145 & $1.02391 \mathrm{E}-05$ \\
Residual & 13 & 6960157989 & 535396768.4 & & \\
Total & 14 & 32737029550 & & &
\end{tabular}

predict the sales, net profit and working capital in TNPL.

\section{REFERENCES}

[1] Brown R. G., 1959. Statistical forecasting for inventory control. New York: McGraw- Hill

[2] Brown R. G., 1962. Smoothing, forecasting and prediction of discrete time series.

[3] Annual Report, Tamilnadu Newsprint and papers Ltd

[4] CMIE, Center for Monitoring Indian Economy.

[5] International Journal of Production Economics, 71, 457466.

[6] Syntetos A.A., Boylan J.E., 2005. The accuracy of intermittent demand estimates.

[7] International Journal of forecasting, 21, 303-314.

\begin{tabular}{lccrrrrrr}
\hline & Coefficients & Standard Error & \multicolumn{1}{c}{ Stat } & P-value & Lower 95\% & Upper 95\% & Lower 95.0\% & Upper 95.0\% \\
\hline Intercept & 217482.87 & 5974.37 & 36.40 & 0.00 & 204576.02 & 230389.71 & 204576.02 & 230389.71 \\
X Variable 1 & 9594.80 & 1382.80 & 6.94 & 0.00 & 6607.45 & 12582.16 & 6607.45 & 12582.16 \\
\hline
\end{tabular}

RESIDUAL OUTPUT

\begin{tabular}{rrr}
\hline Observation & \multicolumn{1}{c}{ Predicted $Y$} & \multicolumn{1}{c}{ Residuals } \\
\hline 1 & 150319.24 & 20298.76 \\
2 & 159914.05 & 16160.95 \\
3 & 169508.85 & 9362.15 \\
4 & 179103.65 & 12002.35 \\
5 & 188698.46 & -4431.46 \\
6 & 198293.26 & -30415.26 \\
7 & 207888.06 & -25673.06 \\
8 & 217482.87 & -21241.87 \\
9 & 227077.67 & 3001.33 \\
10 & 236672.47 & -5511.47 \\
11 & 246267.28 & -796.28 \\
12 & 255862.08 & -959.08 \\
13 & 265456.88 & -20448.88 \\
14 & 275051.69 & -10007.69 \\
15 & 284646.49 & 58659.51 \\
\hline
\end{tabular}

PROBABLITY OUTPUT

\begin{tabular}{rr}
\hline Percentilt & \multicolumn{1}{l}{} \\
\hline 3.3 & 167878 \\
10.0 & 170618 \\
16.7 & 176075 \\
23.3 & 178871 \\
30.0 & 182215 \\
36.7 & 184267 \\
43.3 & 191106 \\
50.0 & 196241 \\
56.7 & 230079 \\
63.3 & 231161 \\
70.0 & 245008 \\
76.7 & 245471 \\
83.3 & 254903 \\
90.0 & 265044 \\
96.7 & 343306 \\
\hline
\end{tabular}

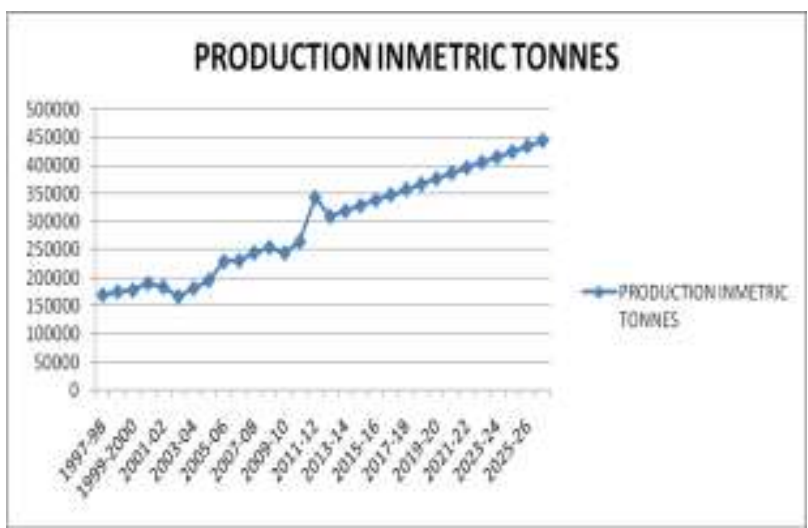

6. CONCLUSION

In this paper, we analyze a Linear Regression Method in forecasting approach to deal with the production data in Tamilnadu Newsprint and papers Ltd. Numerical experiments show that the next 15 years forecasting production in that company. For further studies, to 